\title{
A Novel Micro RNA Feedback Loop of High Mobility Group Protein A1a in Regulating Estrogen Receptor Alpha Alternative Splicing
}

\author{
Kenji Ohe $^{1 *}$, Yoshihiro Harada ${ }^{1}$, Yuta Horita ${ }^{1}$, Hiroyoshi Harada ${ }^{1}$, Hiroki Terai ${ }^{1}$, Masayoshi Mori ${ }^{1}$, Yusuke Murata ${ }^{1}$, \\ Kenji Ashida ${ }^{2}$, Munechika Enjoji ${ }^{1}$ \\ ${ }^{1}$ Department of Pharmacotherapeutics, Faculty of Phamaceutical Sciences, Fukuoka University, Fukuoka city, Japan \\ ${ }^{2}$ Division of Endocrinology and Metabolism, Department of Internal Medicine, Kurume University School of Medicine, Kurume city, Japan
}

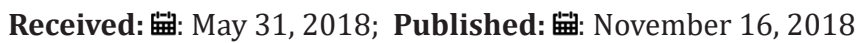

*Corresponding author: Kenji Ohe, Department of Pharmacotherapeutics, Faculty of Pharmaceutical Sciences, Japan

\begin{abstract}
The hER $\alpha$ gene is known for its major role in estrogen dependent growth of breast cancer. ER $\alpha$ positivity is a hallmark in treating these cancers. Though there are many isoforms reported for hER $\alpha$, the splicing regulation, especially for the 5 ' non-coding exons is largely unknown. We have recently reported that the oncogenic product, high-mobility-group protein A1a (HMGA1a) can induce the expression of hER $\alpha 46$ through regulating alternative splicing of the hER $\alpha$ gene. An RNA decoy of HMGA1a can reverse this splicing event as well as alter estrogen responsiveness of MCF-7 breast cancer cells. Here, we will review on the emerging issue of HMGA1a as a sequence-specific RNA-binding protein and show experimental evidence of the HMGA1a RNA-binding site found in the seed sequence of a microRNA and possible feedback loop.

Keywords: ER $\alpha$ Gene; Hmga1a; Non Coding Exon; Splicing Regulation; Microrna; Tamoxifen Resistance

Abbreviations: HERa: Human Estrogen Receptor Alpha; HGRa: Human Glucocorticoid Receptor Alpha; HMGA1a: High Mobility Group Protein A1a; HPS2: Human Presenilin-2; PR: Progesterone Receptor; FOS: FBJ Murine Osteosarcoma Viral Oncogene Homolog; TFF1: Trefoil Factor 1; ERBB2: v-erb-b2 Avian Erythroblastic Leukemia Viral Oncogene Homolog 2; Her2, Human Epidermal Growth Factor Receptor 2; miR-16: MicroRNA 16; mir21: microRNA 21; RNU-6: U6 Small Nuclear RNA
\end{abstract}

\section{Materials and Methods}

\section{Oligonucleotides and Antibodies (Table 1)}

Table 1: Oligonucleotides used for RT-PCR are: Oligonucleotides and antibodies.

\begin{tabular}{|c|c|c|}
\hline \multirow{2}{*}{$\begin{array}{l}\text { Full Length } \\
\text { ER } \alpha 66\end{array}$} & exon3f & 5'-GGGAATGATGAAAGGTGGCTTTGTGG-3' \\
\hline & exon8r & 5'-TATGACCTGCTGCTGGAGATGCTGG-3' \\
\hline \multirow{2}{*}{$\begin{array}{l}\text { Progesterone } \\
\text { Receptor } \\
\text { (PGR) }\end{array}$} & PGR941f & 5'-ACAGGACCCCTCCGACGAAAA-3' \\
\hline & PGR1269r & 5'-AGCTGTCTCCAACCTTGCACC-3' \\
\hline \multirow{2}{*}{$\begin{array}{l}\text { FBJ Murine } \\
\text { Osteosarcoma } \\
\text { Viral } \\
\text { Oncogene } \\
\text { Homolog } \\
\text { (FOS) }\end{array}$} & cFOS227f & 5'-GGATAGCCTCTCTTACTACCAC-3' \\
\hline & cFOS506r & 5'-TCCTGTCATGGTCTTCACAACG-3' \\
\hline \multirow{2}{*}{$\begin{array}{c}\text { Trefoil Factor } \\
1 \text { (TFF1) }\end{array}$} & TFFf & 5'-GAGAACAAGGTGATCTGCGC-3' \\
\hline & TFFr & 5'-TGGTATTAGGATAGAAGCACC-3' \\
\hline
\end{tabular}

\section{Total RNA and Protein Extraction from MCF-7 Tumors}

MCF-7 tumors were removed from transplanted nude mice and quickly frozen in liquid nitrogen. The tumors were crushed into small pieces and put into an Eppendorf tube with TRIzol reagent (Invitrogen). The tissue was grinded with a disposable grinder and total RNA, protein was purified following the manufacturer's instruction of TRIzol reagent. In brief, after passing the extract through a $25 \mathrm{G}$ needle five times, the sample was centrifuged.

\section{RT-PCR and Immunoblot Analyses}

For RT-PCR, the aqueous phase was precipitated by isopropanol treated by RQ1 DNase (Promega, M6101) and total RNA was precipitated. One $\mu \mathrm{g}$ of total RNA was subjected to reverse transcription by Rever Tra Ace (TRT-101) and $0.5 \mu$ l of the reverse transcribed product was subjected to subquantitative PCR (25 to 30 cycles) by TaKaRa Ex Taq (TaKaRa Bio, RR001A). For immunoblot 
assays, protein was purified from the interphase and organic phase by precipitating with $6 \mathrm{~V}$ of a solution for precipitating protein (50\% Ethanol, 24.5\% Acetone, 24.5\% Methanol, 1\% distilled water). Twenty micrograms of protein were boiled in sample buffer and separated by 10\% sodium dodecyl sulfate-PAGE (SDSPAGE), transferred to a PVDF membrane and analyzed by primary antibodies: ER $\alpha$ antibody (HC-20) (Santa-Cruz, sc-543) or HMGA1a antibody (Santa Cruz, FL95) and appropriated secondary antibodies and revealed by Chemi-Lumi One L (Nacalai Tesque, 07880-54).

\section{Micro RNA Expression Analyse}

For micro-RNA expression analyses, total RNA was reverse transcribed by miScript II RT Kit (QIAGEN, 218160) and miR-16, miR-21, RNU-6 was amplified by miScript Primer Assay (QIAGEN, 218300).

\section{Introduction}

Multiple non-coding exons are frequently found in the 5' region of hormone receptor genes. Most typical are hER $\alpha$ and hGR $\alpha$ (Figure 1). The hER $\alpha$ gene is encoded of eight exons with five 5 ' non-coding exons, exons $\mathrm{F}$ to $\mathrm{B}$ from $5^{\prime}$ to 3 ', that form $\mathrm{F}$ to B hER $\alpha$ mRNA in addition to A hER $\alpha$ mRNA that is transcribed immediately upstream of exon 1 [1]. More non-coding exons were found with other numerous variants for hER $\alpha$ [2-4] (Figure 1A). Likewise, the hGR $\alpha$ gene is encoded of nine exons with eight $5^{\prime}$ non-coding exons. Non- coding exon $1 \mathrm{~A}$ is far upstream and activated by glucocorticoids [5]. The rest are expressed in a tissue specific manner with exons 1-D, 1-E, 1-B, 1-F, 1-C, 1-H from 5' to 3'. The ABCs are the order they were discovered [6] (Figure 1B). The regulation of multiple non-coding exons in the $5^{\prime}$ region of genes involves alternative splicing as well alternative promoter selection. We have found a factor, HMGA1a, previously known as a DNA-binding protein and oncogenic product that binds RNA in a sequence-specific manner and regulates alternative splicing of the ER $\alpha$ gene $[7,8]$. The 5' splice site of the hGR $\alpha$ variant exon 1-D has a HMGA1a RNA-binding site adjacently upstream the 5' splice site (5'-UGCCGCACAAGgu-3'). This hGR $\alpha$ HMGA1a RNA-binding site resembles the original HMGA1a RNAbinding site adjacently upstream the $5^{\prime}$ splice site of hPS2 exon 5 (5'-GCUGCUACAAGgu-3') [9,10] and the one adjacently upstream the pseudo-5' splice site of hER $\alpha$ exon 1 (5'-GCGGCUACACGgu-3') $[7,8]$ with a GC-rich stretch followed by common nucleotides shown in bold and underlined (Figure 2A). It has recently been reported that HMGA1a binds stems of 7SK RNA (5'---CCG---loop---CGG---3'; the HMGA1a binding site is underlined) [11] (Figure 2B). As for hGR $\alpha$ exon 1-D, a CGG trinucleotide can be found $17 \mathrm{nt}$ downstream the CCG trinucleotide found in the hGR $\alpha$ exon 1-D HMGA1a RNAbinding site. However, this kind of HMGA1a RNA-binding site could not be found for the HMGA1a RNA-binding site in PS2 exon 5 or hER $\alpha$ exon 1.

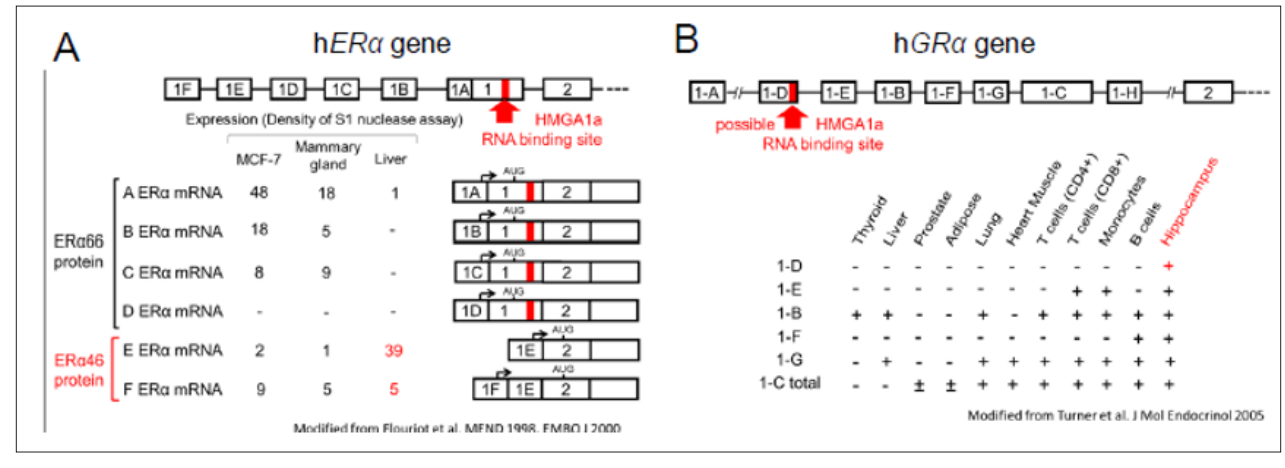

Figure 1: Multiple 5' non-coding exons of the hERa and hGRa genes and HMGA1a RNA-binding site.

A. Structure of the $h E R$ gene showing tissue distribution of each isoform.

B. Structure of the hGR gene showing tissue distribution of each isoform.

C. Comparison of HMGA1a RNA-binding sites in hPS2 exon 5 and hERa exon 1 with the one yet to be confirmed in hGRa exon 1-D.

D. The HMGA1a RNA-binding site (red letters) found in 7SK RNA.

\begin{tabular}{|c|c|c|c|c|}
\hline \multicolumn{4}{|l|}{ A } & \multirow{3}{*}{$\begin{array}{lll}B & c G & \\
{ }_{130}{ }_{G}{ }^{C} & \text { part of } \\
& G & 7 \text { SK RNA }\end{array}$} \\
\hline \begin{tabular}{|l|} 
Target exon \\
\end{tabular} & HMGA1a RNA-binding site & \begin{tabular}{|l|} 
disease \\
\end{tabular} & refs & \\
\hline hPS2 exon 5 & $5^{\prime}$-GCUGCUACAAGgu-3' & Sporadic Alzheimer disease & {$[9,10]$} & \\
\hline hERa exon 1 & 5'-GCGGCUACACGgu-3' & Breast Cancer & {$[7,8]$} & \\
\hline hGRa exon 1-D & 5'-UGCCGCACAAGgu-3' & $?$ & & \\
\hline
\end{tabular}

Figure 2: HMGA1a RNA-binding sites.

A. Comparison of HMGA1a RNA-binding sites in hPS2 exon 5, hERa exon 1, and the one yet to be defined in hGRa exon 1-D.

B. The HMGA1a RNA-binding site (red letters) in 7SK RNA. 
This HMGA1a RNA-binding site was originally discovered as a factor binding adjacently upstream the 5' splice site of PS2 exon 5 [9]. PS2 as well as Presenilin-2 and amyloid-precursor-protein are known to harbor mutations in familial Alzheimer's disease $[12,13]$. The challenge was to seek for alternative spliced variants of these genes in the brain of sporadic Alzheimer's disease patients. A relentless search for aberrantsplicing variants found one for PS2 exon 5 [14]. The patients who harbor these aberrantly spliced PS2 exon 5 isoform showed vulnerability to endoplasmic reticulum stress and increased production of beta-amyloid [15]. In a pursuit to identify the factor responsible of this exon-skipping, HMGA1a was found to bind a region adjacently upstream the $5^{\prime}$ splice site of PS2 exon 5. HMGA1a interacted with U1-70K, a component of the U1 snRNP that is important for 5' splice site recognition by the spliceosome (splicing complex). HMGA1a was expressed in splicing speckles of the cell and showed increased expression in the CA1 region of the hippocampus [9] just as the resulting spliced product, PS2V did (70\% of sporadic Alzheimer's disease patients' brains compared to $17.6 \%$ of control brains [14].

However, it was puzzling because when HMGA1a was added to a purified U1 snRNP/ 5' splice site RNA reaction, the recognition was improved. Carefully looking over the splicing reaction, it crossed our minds that U1 snRNP needed to dissociate to carry on the spicing reaction. Indeed, itwas the trapping of U1 snRNPby HMA1athatmade HMGA1a inhibit splicing and induce exon-skipping. Remarkably, this effect was only found when the HMGA1a RNA binding site was adjacent the 5' splice site [10]. In a search for other targets for HMGA1a, the human estrogen receptor alpha (hER $\alpha$ ) gene came to our minds, because a vast list of literature had been reporting the relation of hER $\alpha$ and HMGA1a in breast cancer cells. First, we made a search (using EMBL-EBI Pairwise Sequence Alignment tool (EMBOSS Needle: https://www.ebi.ac.uk/Tools/psa/emboss_ needle/nucleotide.html)) for the PS2 HMGA1a RNAbinding site with a gu at the 3 ' terminal end (5'-GCUGCUACAAGgu-3') in the $\mathrm{hER} \alpha$ gene. We found a candidate in hER $\alpha$ exon1, $33 \mathrm{nt}$ upstream the authentic 5' splice site. Exon-skipping of hER $\alpha$ exon1 would result in a shorter isoform lacking the AF- 1 domain of hER $\alpha$ called hER $\alpha 46$. A transcript consisted of 5' non-coding exons E and/ or $F(E / F$ ER $\alpha$ mRNA) also skips exon 1 [1]. Overexpression of HMGA1a induced exon-skipping of the endogenous hER $\alpha$ gene.
We transiently expressed a decoy of the HMGA1a RNA binding site (bold) with a microRNA nucleus localization signal (underlined) at its 3' end (5'-GCUGCUACAAGAGUGUU [16]. This HMGA1a RNA decoy efficiently blocked HMGA1a-induced skipping of hER $\alpha$ exon1 [10]. We also pursued the mechanism of this exon-skipping. Unlike PS2 exon 5, the 5' splice site adjacent the HMGA1a RNA binding site is $33 \mathrm{nt}$ upstream the authentic 5' splice site. Using psoralen UV crosslinking combined with RNA-EMSA, we were able to show that HMGA1a trapped U1 snRNP at the upstream but not the authentic 5' splice site [8]. We believe the 5' splice site of the hGR $\alpha$ variant exon 1-D will work in a similar manner. It is known well that exon 1-D is expressed exclusively in the hippocampus along with all other $\mathrm{hGR} \alpha$ exon 1s, and that exon 1-D is important for neuron-specific expression of hGR $\alpha$ [17].

The expression of exon 1-D is possibly regulated by the Ying Yang 1(YY1) transcription factor [6]. YY1 is known to enhance the expression of APBB1 (amyloid beta precursor protein binding family B member 1), a factor whose expression level correlates with the risk of developing, and severity of late-onset Alzheimer's disease $[18,19]$. Thus, the target of HMGA1a may also be exon 1-D of hGR $\alpha$. Indeed, in senescence accelerated mouse (SAM) [20] the expression of GR $\alpha$ was found to be attenuated [21]. The importance of the GR $\alpha$ signaling pathway can be found in Addison's disease patients where impaired episodic memory is a frequent symptom [22].

\section{Results}

One important target of HMGA1a RNA binding site is microRNA. In a search of a seed sequence of microRNA that may resemble the HMGA1a RNA binding site, we found miR-16 as a candidate. In theory, HMGA1a would bind to the antisense strand of miR-16 in its pre-primary miR (Figure 3A) (boxed) and impair its maturation. This would result in further enhanced HMGA1a expression because HMGA1a is one of miR-16 targets [23]. A decoy RNA of HMGA1a RNA-binding site (Figure 3A) (blue letters) would bind the seed sequence of miR-16 and would also inhibit the function of miR-16. The primary miR-16 in the nucleus, as a stem loop, has no $5^{\prime}$-CCG-3' and complementary 5'-CGG-3' sequence as 7SK RNA (Figures 3B \& 2B).

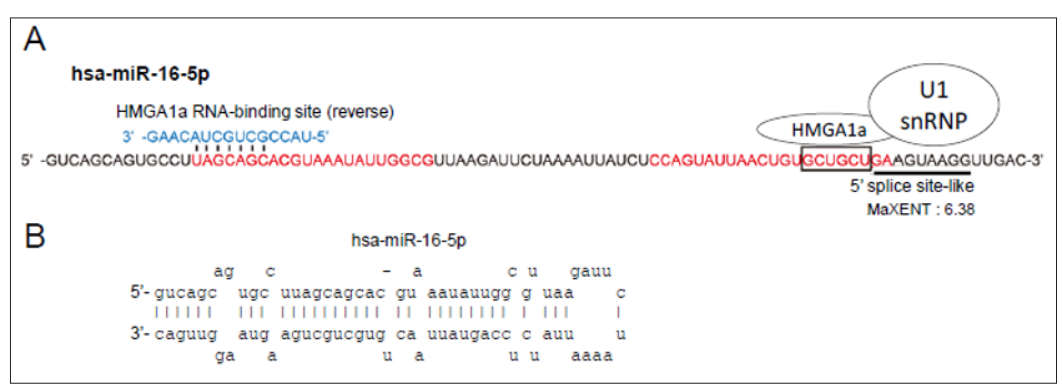

Figure 3: Predicted HMGA1a RNA-binding site in miR-16.

A. HMGA1a RNA-binding site (black box) in human pre-primary-miR-16 (mature miR-16 in red letters) (hsa-miR-16-5p). HMGA1a RNA-binding site shown as reversed sequence (blue letters) and complementarity to seed sequence of miR-16.

B. hsa-miR-16-5p as pre micro-RNA. 

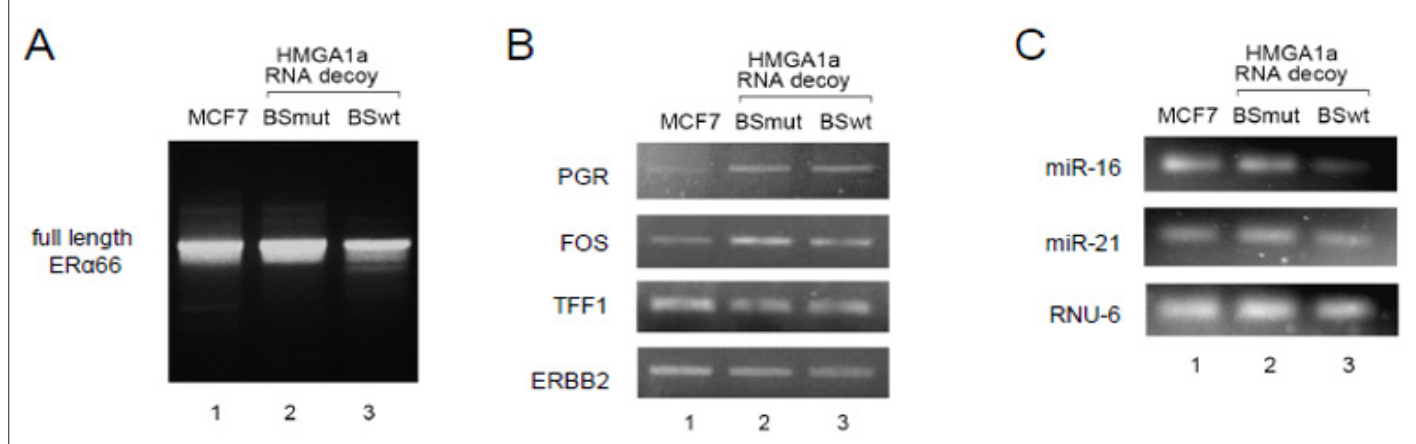

Figure 4: Expression of ERa and its target as well as miR-16 in stably expressed HMGA1a RNA decoy of MCF-7 tumors.

A. Expression of full length ERa66 mRNA,

B. Expression of ERa-target genes: PR, FOS, TFF1, and ERBB2.

C. Expression of miR-16, miR-21, and control: RNU-6. The control of A and B are also referred to RNU-6.

To test the relation of miR-16 and HMGA1a RNA-binding function, we checked its expression in the tumors of stably expressed MCF-7 cells of the HMGA1a RNA decoy transplanted into nude mice [7] as well as well as full length $C$ type isoform of $\mathrm{ER} \alpha$ expressed in mammary tissue and ER $\alpha$ target genes. To our surprise, the expression of the $C$ type full length $E R \alpha$ was slightly lower in HMGA1a RNA decoy-expressed cells (Figure 4A). Thus, we also checked the expression of ER $\alpha$ target genes: PGR (progesterone receptor); FOS (FBJ murine osteosarcoma viral oncogene homolog); TFF1 (trefoil factor); and ERBB2 (v-erb-b2 avian erythroblastic leukemia viral oncogene homolog 2, also known as Her2 (human epidermal growth factor receptor 2)) but could find no differential expression with the control decoy RNA (Figure 4B) (lane 2 \& 3). We though that the decreased expression of full length ER $\alpha$ may have increased its expression to compensate the low expression of type C full length ER $\alpha$ to maintain the expression of ER $\alpha$ target genes. We also checked the expression of micro RNAs, especially HMGA1a targeting miR16, in these HMGA1a RNA decoy stably expressed MCF-7 tumors. As expected, the expression of miR16 decreased (Figure 4C) probably because of the HMGA1a RNA decoy. However, the HMGA1a RNA decoy would also bind HMGA1a to prevent its binding to the antisense strand of primary miR-16. This makes the function of HMGA1a RNA decoy complicated due to its biphasic effect on miR-16 expression; binding to the seed sequence of miR-16; and binding to HMGA1a to prevent HMGA1a RNA-binding to the antisense strand of primary miR-16. In this respect, the expression of ER $\alpha 46 / E R \alpha 66$ mRNA ratio may not be the same as prior transplantation. Thus, we checked expression ER $\alpha 46$ and ER $\alpha 66$ protein in stably expressed HMGA1a RNA decoy of MCF-7 tumors, we found the expression reversed (Figure 5A) (upper panel) compared to prior transplantation [7].

Briefly, HMGA1a RNA decoy is known to decrease the HMGA1ainduced aberrantly spliced ER $\alpha 46$ mRNA and increase the type $\mathrm{D} / \mathrm{F}$ full length ER $\alpha 66$ mRNA and concomitant protein level in MCF-7 cells as we have reported [7]. We checked whether HMGA1a protein was re-expressed due to the decreased miR-16 expression by HMGA1a RNA decoy, and this was indeed the case (Figure 5A) (lower panel). The expression of ER $\alpha 46$ and ER $\alpha 66$ mRNA showed the same results (Figure 5B). The mechanism of this reversed effect may be due to the biphasic function of HMGA1a RNA decoy expressed above, but maybe simply due to reduced effect of the HMGA1a RNA decoy because it is easy to imagine that stably expressed would be much lower than transiently expressed. However, this would only decrease the ratio and would not reverse ER $\alpha 46$ and ER $\alpha 66$ or induce HMGA1a expression.

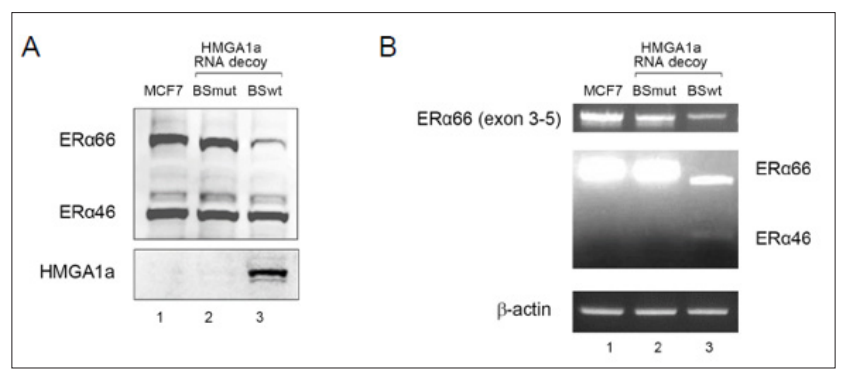

Figure 5: Reversed effect of HMGA1a RNA decoy.

A. HMGA1a RNA decoy stably expressed MCF-7 tumors exhibit a reversed effect of ERa46 and ERa66 protein ratio (upper panel), due to re-expression of HMGA1a (lower panel).

B. The reversed effect of ERa46 and ERa66 mRNA ratio by HMGA1a RNA decoy stably expressed in MCF-7 tumors. 


\section{Discussion}

We have reported the first splicing factor that regulates splicing of 5' non-coding exons of the ER $\alpha$ gene. An HMGA1a RNA decoy inhibits HMGA1a RNA-binding function, reduce ER $\alpha 46$ expression, and sensitize MCF cells to tamoxifen by the restored estrogendependent growth [7]. Since HMGA1a is also known as a DNAbinding factor, in vitro splicing assays were performed to exclude the possible regulation through promoter selection [8]. Here, we show that the seed sequence of miR-16, an HMGA1a-targeting micro-RNA, is complementary to the HMGA1a RNA-binding site. Since it is known that increase of HMGA1a expression in cancer cells increase its malignant potential [24] the increased HMGA1a may decrease its own targeting miR-16 by binding to the antisense strand of primary miR-16.

This possible miR-16-mediated RNA-binding feedback loop of HMGA1a (Figure 6) also explains the results we showed here. Prior to transplantation, HMGA1a RNA decoy prevents the HMGA1ainduced exon-skipping of ER $\alpha$ exon 1 in MCF-7 cells [7] and by in vitro splicing assays [8]. However, the long incubation period of cloning stable MCF-7 transfectants of HMGA1a RNA decoy induces exon-skipping rather than exon-inclusion by inducing HMGA1a expression (Figure 5) a result of attenuated miR-16 expression (Figure 4C). A feedback loop mediated by micro-RNA has been reported for SF2/ASF (SRSF1) [25]. The micro-RNA feedback loop of HMGA1a is the second of such to be reported and differs in that it negatively regulates its own targeting micro-RNA. The limitations of this study is that we have not shown direct in vitro analyses of HMGA1a binding to the primary miR-16. Future studies will focus on the simple induction of miR-16 in tamoxifen-resistant MCF-7 (TAMR1) cells that may lower HMGA1a expression and its RNAbinding properties.

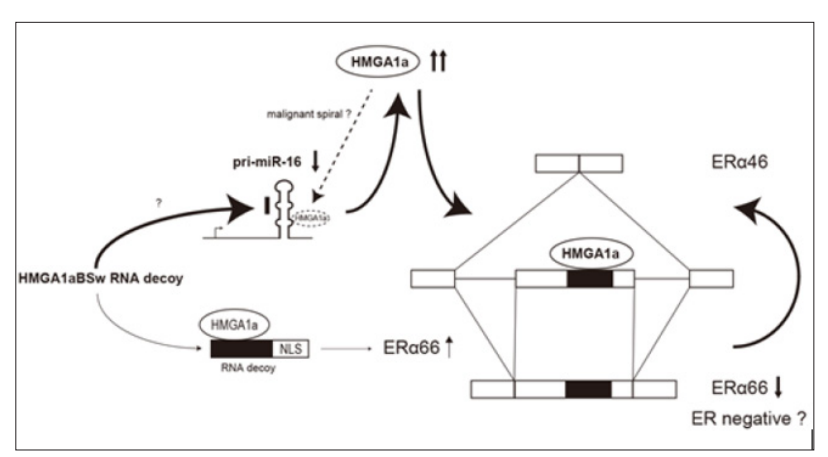

Figure 6: Predicted feedback model of HMGA1a RNA decoy via miR-16.

\section{Author contributions}

KO conducted all the experiments and wrote the manuscript $Y$ Ha, YHo, YB, HH, HT, MM, YM, TT, MT, IA, KA, KK, TN, TU, TY, ME with assist of KO and Ta Y, KO. Wrote the paper. IA, MT, TN, KK, ME, TY supervised and arranged the experiments.

\section{References}

1. Flouriot G, Brand H, Denger S, Metivier R, Kos M, et al. (2000) Identification of a new isoform of the human estrogen receptor-alpha
(hER-alpha) that is encoded by distinct transcripts and that is able to repress hER-alpha activation function 1. EMBO J 19(17): 4688-4700.

2. Kobayashi M, Ishii H, Sakuma Y (2011) Identification of novel splicing events and post-transcriptional regulation of human estrogen receptor alpha F isoforms. Mol Cell Endocrinol 333(1): 55-61.

3. Okuda Y, Hirata S, Watanabe N, Shoda T, Kato, J et al. (2003) Novel splicing events of untranslated first exons in human estrogen receptor alpha (ER alpha) gene. Endocr J 50(1): 97-104.

4. Ishii H, Kobayashi M, Munetomo A, Miyamoto T, Sakuma Y (2013) Novel splicing events and post-transcriptional regulation of human estrogen receptor alpha E isoforms. J Steroid Biochem Mol Biol 133: 120-128.

5. Breslin MB, Geng, CD, Vedeckis WV (2001) Multiple promoters exist in the human GR gene, one of which is activated by glucocorticoids. Mol Endocrinol 15(8): 1381-1395.

6. Turner JD, Muller CP (2005) Structure of the glucocorticoid receptor (NR3C1) gene 5' untranslated region: identification, and tissue distribution of multiple new human exon 1. J Mol Endocrinol 35: 283292.

7. Ohe K, Miyajima S, Abe I, Tanaka T, Hamaguchi Y, et al. (2018) HMGA1a induces alternative splicing of estrogen receptor alpha in MCF-7 human breast cancer cells. J Steroid Biochem Mol Biol 182: 21-26.

8. Ohe K, Miyajima S, Tanaka T, Hamaguchi Y, Harada Y, et al. (2018) HMGA1a Induces Alternative Splicing of the Estrogen Receptoralphalpha Gene by Trapping U1 snRNP to an Upstream Pseudo-5' Splice Site. Front Mol Biosci 5: 52.

9. Manabe T, Katayama T, Sato N, Gomi F, Hitomi J, et al. (2003) Induced HMGA1a expression causes aberrant splicing of Presenilin-2 pre-mRNA in sporadic Alzheimer's disease. Cell Death Differ 10(6): 698-708.

10. Ohe K, Mayeda A (2010) HMGA1a trapping of U1 snRNP at an authentic 5 ' splice site induces aberrant exon skipping in sporadic Alzheimer's disease. Mol Cell Biol 30(9): 2220-2228.

11. Eilebrecht S, Brysbaert G, Wegert T, Urlaub H, Benecke BJ, et al. (2011) 7SK small nuclear RNA directly affects HMGA1 function in transcription regulation. Nucleic Acids Res 39(6): 2057-2072.

12. Goate A, Chartier Harlin MC, Mullan M Brown J, Crawford F, Fidani L, et al. (1991) Segregation of a missense mutation in the amyloid precursor protein gene with familial Alzheimer's disease. Nature 349: 704-706.

13. Rogaev EI, Sherrington R, Rogaeva EA, Levesque G, Ikeda M, et al. (1995) Familial Alzheimer's disease in kindreds with missense mutations in a gene on chromosome 1 related to the Alzheimer's disease type 3 gene. Nature 376(6543): 775-778.

14. Sato N, Hori O, Yamaguchi A, Lambert JC, Chartier Harlin MC, et al. (1999) A novel presenilin-2 splice variant in human Alzheimer's disease brain tissue. J Neurochem 72(6): 2498-2505.

15. Sato N, Imaizumi K, Manabe T, Taniguchi M, Hitomi J, et al. (2001) Increased production of beta-amyloid and vulnerability to endoplasmic reticulum stress by an aberrant spliced form of presenilin 2. J Biol Chem 276(3): 2108-2114.

16. Hwang HW, Wentzel EA, Mendell JT (2007) A hexanucleotide element directs microRNA nuclear import. Science 315(5808): 97-100.

17. Turner JD, Schote AB, Macedo JA, Pelascini LP, Muller CP (2006) Tissue specific glucocorticoid receptor expression, a role for alternative first exon usage? Biochem Pharmacol 72(11): 1529-1537.

18. Lambert JC, Mann D, Goumidi L, Harris J, Pasquier F, et al. (2000) A FE65 polymorphism associated with risk of developing sporadic late-onset alzheimer's disease but not with Abeta loading in brains. Neurosci Lett 293: 29-32.

19. Delatour B, Mercken L, El Hachimi KH, Colle MA, Pradier L, et al. (2001) E65 in Alzheimer's disease: neuronal distribution and association with neurofibrillary tangles. Am J Pathol 158(5): 1585-1591. 
20. Yagi H, Katoh S, Akiguchi I, Takeda T (1988) Age-related deterioration of ability of acquisition in memory and learning in senescence accelerated mouse: SAM-P/8 as an animal model of disturbances in recent memory. Brain Res 474(1): 86-93.

21. Wei X, Zhang Y, Zhou J (1999) Alzheimer's disease-related gene expression in the brain of senescence accelerated mouse. Neurosci Lett 268(3): 139-142.

22. Henry M, Thomas KG, Ross IL (2014) Episodic memory impairment in Addison's disease: results from a telephonic cognitive assessment. Metab Brain Dis 29(2): 421-430.

ISSN: 2574-1241

DOI: $10.26717 / B J S T R .2018 .11 .002058$

Kenji Ohe. Biomed J Sci \& Tech Res

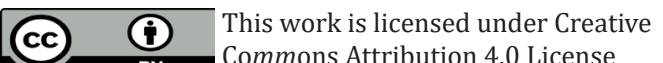

Submission Link: https://biomedres.us/submit-manuscript.php
23. Kaddar T, Rouault JP, Chien WW, Chebel A, Gadoux M, et al. (2009) Two new miR-16 targets: caprin-1 and HMGA1, proteins implicated in cell proliferation. Biol Cell 101(9): 511-524.

24. Tallini G, Dal Cin P (1999) HMGI(Y) and HMGI-C dysregulation: a common occurrence in human tumors. Adv Anat Pathol 6(5): 237-246.

25. Wu H, Sun S, Tu K, Gao Y, Xie B, et al. (2010) A splicing-independent function of SF2/ASF in microRNA processing. Mol Cell 38(1): 67-77.

$\begin{array}{ll}\text { BIOMEDICAL } & \text { Assets of Publishing with us } \\ \text { RESEARCHES } & \text { - Global archiving of articles } \\ \text { - Immediate, unrestricted online access } & \text { - Rigorous Peer Review Process } \\ & \text { - Authors Retain Copyrights }\end{array}$

